\title{
Biliary Bile Acid Composition of the Human Fetus in Early Gestation
}

\author{
C. COlOMBo, G. ZUliani, M. RONCHI, J. BREIDENSTEIN, AND K. D. R. SETCHELL \\ Department of Pediatrics and Obstetrics, University of Milan, Milan, Italy [C.C., G.Z., M.R.J and Department of \\ Pediatric Gastroenterology and Nutrition, Children's Hospital Medical Center, Cincinnati,
} Ohio 45229 [J.B., K.D.R.S.]

\begin{abstract}
Using analytical techniques, which included capillary column gas-liquid chromatography and mass spectrometry, detailed bile acid profiles were obtained for 24 fetal bile samples collected after legal abortions were performed between the 14th and 20th wk of gestation. Qualitatively, the bile acid profiles of all fetal bile samples were similar. The predominant bile acids identified were chenodeoxycholic and cholic acid. The presence of small but variable amounts of deoxycholic acid and traces of lithocholic acid suggested placental transfer of these bile acids from the maternal circulation. $3 \beta$-Hydroxy-5-cholenoic acid was detected at higher levels than lithocholic acid. A conspicuous feature of the profiles was the presence of bile acids with hydroxyl groups at positions $\mathrm{C}-1$ and $\mathrm{C}$ 6 , and one other nuclear position of unknown origin, indicating fetal hepatic synthesis via pathways different from those normally seen in the adult. Quantitatively total biliary bile acid concentrations were extremely low $(<0.05$ $\mathrm{mM}$ ) before wk 17 of gestation, but thereafter concentrations markedly increased reflecting a possible surge in bile acid synthesis; however, the ratio of cholic:chenodeoxycholic acids remained relatively constant over this period (mean $\pm S D=0.85 \pm 0.36$ ) and different from that reported for the healthy newborn (ca. 2.5) and adult (ca. 1.6). These data indicate an immaturity in hepatic $12 \alpha$ hydroxylation of bile acids during early development and may explain why other pathways, in particular $1 \beta$ and $6 \alpha-$ hydroxylation, are activated at this stage of life. (Pediatr Res 21: 197-200, 1987)
\end{abstract}

\section{Abbreviations}

Me-TMS, methyl ester-trimethylsilyl

GLC, gas-liquid chromatography

MS, mass spectrometry

Only limited studies have been performed in the human infant to define the development of bile acid synthesis and metabolism during early life (1-10) and these have been the subject of reviews, $(11,12)$. A greater insight of the ontogeny of bile acid metabolism is essential to aid in the understanding of nutritional problems related to fat malabsorption in the normal, and above all, the premature newborn. A state of physiologic cholestasis has been defined during the first months of life $(13-15)$, but the exact mechanisms responsible are not completely understood, save the demonstration in animal models of an immaturity of several of

Received June 20. 1986: accepted October 7, 1986. Reprint requests and correspondence Dr. K. D. R. Setchell, Children's Hospital Medical Center, Cincinnati, $\mathrm{OH} 45229-2899$ the key processes of the enterohepatic circulation of bile acids (16-19). As a result of physiologic cholestasis, the newborn infant has a tendency to develop a true neonatal cholestasis when subjected to such stresses as sepsis, hypoxia, and total parenteral nutrition (15).

Abnormalities in bile acid metabolism have been suggested to be a factor in the development of certain forms of cholestasis in the newborn (20) and in animal models the hepatotoxic nature of bile acids has been well established (21-24). A greater understanding of the etiology of these conditions requires a better knowledge of bile acid metabolism in the human fetus and in the newborn infant.

Previous studies of bile acid concentrations of maternal and fetal serum in early gestation suggest that the synthesis of bile acids is reasonably well developed. This study extends these previous observations to examine the bile acid composition of human fetal bile during the same period of gestation, but utilized more sophisticated analytical techniques, including capillary GLC-MS (26-32).

\section{EXPERIMENTAL}

Collection of fetal bile. Gallbladders were obtained from 24 human fetuses immediately after legal abortion, performed between the 14th and 20th wk of gestation in Italy. All of the pregnancies were uncomplicated until the time they were interrupted and none of the mothers had obvious organic diseases (including gastrointestinal and hepatic abnormalities). Fetal age was assessed on the basis of clinical history as well as by means of ultrasound. All abortions were performed through suction and none of the mothers received prostaglandins, phenobarbital, or other drugs know to influence bile acid metabolism. After the liver was removed, the cystic duct was tied and the gallbladder was immediately isolated. Gallbladder bile was then aspirated using a 100- $\mu$ l syringe and the volume of bile was recorded in each case and frozen within $5 \mathrm{~min}$ of completion of the abortion. Bile acids were isolated from the bile samples by liquid-solid extraction (26) as described below and analyzed by previously reviewed techniques (26-29).

Analysis of fetal bile. Fetal bile (10-100 $\mu \mathrm{l})$ was diluted in 1 $\mathrm{ml}$ with distilled water and $0.1 \mathrm{M}$ sodium hydroxide $(4 \mathrm{ml})$ was added. The sample was heated to $64^{\circ} \mathrm{C}$ and bile acids and their conjugates were extracted using reverse phase octadecylsilane bonded silica cartridges (Bond Elut) as described previously (26, 29). Conjugated bile acids were hydrolyzed, first by solvolysis at $37^{\circ} \mathrm{C}$ for $24 \mathrm{~h}$ in a mixture of methanol $(9 \mathrm{ml})$ :acetone $(1 \mathrm{ml}): 6$ $\mathrm{N} \mathrm{HCl}, 3$ drops followed by an overnight enzymatic hydrolysis at $37^{\circ} \mathrm{C}$ with cholylglycine hydrolase from Clostridia perfringens (50 $\mathrm{U}$ in $2 \mathrm{ml}$ of $0.1 \mathrm{M}$ phosphate buffer $\mathrm{pH} 5.8$ ). The $\mathrm{pH}$ of the hydrolysate was adjusted to $\mathrm{pH} 3-4$ and passed through a column of Lipidex 1000, where unconjugated (or hydrolyzed) bile acids are retained by the gel $(26,30)$. Elution of the gel with $68 \%$ 
methanol $(20 \mathrm{ml})$ afforded a means of recovering bile acids, separately from monohydroxy sterols which are retained in this reverse phase solvent system. After addition of an internal standard (1-10 $\mu \mathrm{g}$ coprostanol depending on sample size) the MeTMS ether derivatives were prepared and the derivative purified by passage through a small column of Lipidex 5000 as detailed elsewhere (26).

Capillary column $G L C$. Bile acids were analyzed as their MeTMS ethers by capillary column GLC on a $30-\mathrm{m} \mathrm{DB}-1$ chemically bonded fused silica column using temperatured programed conditions from $225-295^{\circ} \mathrm{C}$ with increments of $2^{\circ} \mathrm{C} / \mathrm{min}$ after an initial isothermal period of $5 \mathrm{~min}$. Helium was used as carrier gas $(2 \mathrm{ml} / \mathrm{min})$ and samples were injected using an all glass dropping needle injector.

Biliary bile acids were quantified by capillary GLC from the ratio of peak height response to the peak height response for the internal standard, coprostanol (26). The sensitivity of the technique is sufficient to detect a bile acid with a concentration of 0.01-0.02 $\mu \mathrm{mol} /$ liter (26).

Capillary column GLC-MS. GLC-MS was performed using a Finnigan 4635 Quadrupole GC-MS system, housing an identical GLC column. The GLC effluent was continuously scanned over the mass range 50-800 D (2 s/cycle) and spectra were generated by electron impact ionization $(70 \mathrm{eV})$. Identification of a bile acid was made on the basis of its complete mass spectrum as compared with an authentic standard and from the GLC retention data. Where authentic compounds were unavailable the identification was based on the predicted fragmentation patterns for the structure $(31,32)$.

\section{RESULTS}

Qualitative analysis. Figure 1 shows a typical GLC profile of the biliary bile acids from the gallbladder bile of an 18-wk fetus. Qualitatively all samples of fetal bile analyzed revealed similar

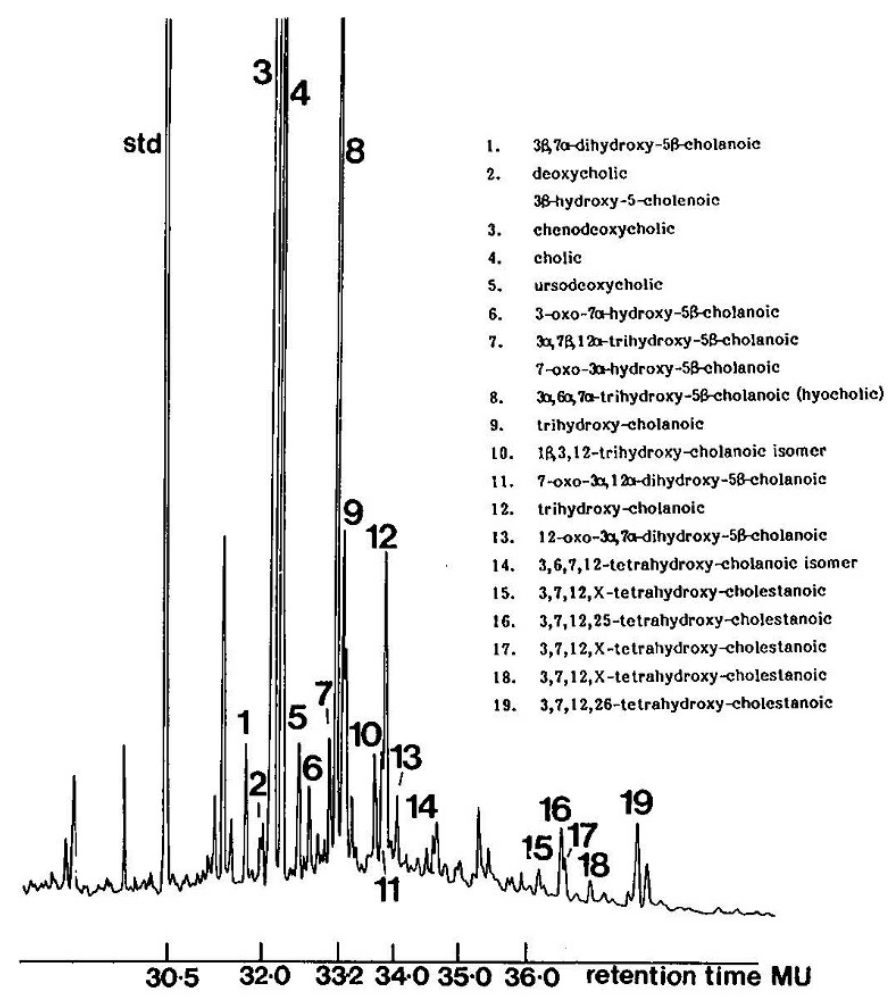

Fig. 1. A typical GLC profile for the total bile acids of human fetal bile obtained at the $18 \mathrm{th}$ wk of gestation. Bile acids were analyzed as their Me-TMS ether derivatives on a $30 \mathrm{~m} \mathrm{DB}-1$ chemically bonded open tubular capillary column by temperature programed operation. profiles. The predominant bile acids identified were chenodeoxycholic and cholic acids. The principal secondary bile acids of adult man, deoxycholic and lithocholic acids, were not present in all samples and when detected, were in low and variable amounts. $3 \beta$-Hydroxy-5-cholenoic acid was always present at low levels but in excess of lithocholic acid.

A conspicuous feature of all profiles was the presence of a wide range of atypical bile acids of which hyocholic $(3 \alpha, 6 \alpha, 7 \alpha$-trihydroxy- $5 \beta$-cholanoic) and a trihydroxy-bile of unknown structure occurred in significant amounts, and together these frequently exceeded the amounts of cholic acid. The mass spectra, the MeTMS ether derivative of this unknown bile acid is shown in Figure 2. The ions at $\mathrm{m} / z 548,458,368$, and 253 are characteristic of a trihydroxy- $5 \beta$-cholanoic structure and the significant ion at $m / z 369$ suggests that two of the hydroxyls are on adjacent carbons $(31,32)$. The significant and prominent ion at $\mathrm{m} / z 181$ may arise from a disubstituted A or B ring structure, but the spectra is not typical of 1-hydroxylated structures, all of which exhibit a diagnostically significant ion at $\mathrm{m} / z 217$, nor is it similar to reported spectra of $2 \beta$-hydroxy bile acids $(7,32)$. Bile acids with 3,6,7-trihydroxy structures have characteristic ions at $\mathrm{m} / z 195$ and 285, not seen in this mass spectrum. An unidentified bile acid with the same series of ions was found in the gastric aspirate from newborn infants $(7,8)$. This mass spectra does not match any of the 98 spectra of bile acids recently compiled (32) and further work is required to elucidate the structure of this quantitatively important compound.

A number of trihydroxy and tetrahydroxy bile acids were present but lack of available authentic compounds makes it difficult to determine their exact structures. Finally, a series of oxo bile acids and tetrahydroxy-cholestanoic acids, the latter with side chain hydroxy groups, were evident.

Quantitative analysis. The concentration of the principal bile acids, cholic and chenodeoxycholic acids measured in fetal bile, obtained between the 14th and 20th wk of gestation, are shown in Figure 3. Values for both bile acids prior to wk 16 of gestation were relatively constant and below $0.05 \mathrm{mM}$ (mean $\pm \mathrm{SD}$ values for cholic acid, $0.020 \pm 0.016 \mathrm{mM}$, and for chenodeoxycholic $0.031 \pm 0.023 \mathrm{mM}, n=6$ ); however, between the 17 th and 20th wk there was a marked increase in the biliary concentration of both bile acids (range $0.026-0.317 \mathrm{mM}$ for cholic acid and $0.017-$ $0.563 \mathrm{mM}$ for chenodeoxycholic acid) reflecting an increase in the range of 20 -fold by the 20 th wk of gestation.

In general chenodeoxycholic acid concentrations exceeded those of cholic acid in bile, but the ratio of the cholic:chenodeoxycholic acid concentrations although variable between samples, remained relatively constant over this period of gestation (Fig. 4). Excluding the two samples obtained from wk 14, which were small in volume and concentration, the mean ratio $( \pm \mathrm{SD})$ for all bile samples irrespective of the gestational age was $0.85 \pm 0.36$.

\section{DISCUSSION}

There are very little data on biliary bile acid composition in the human fetus, and studies which have examined this issue $(2$, 4) were carried out in the early 1960 s when analytical techniques were less advanced than those now available. Poley et al. (2) in 1964 described for the first time the biliary bile acid composition of three human fetuses at age 22-28 wk of gestation and reported a predominance of chenodeoxycholic acid compared with cholic acid up to the 28 th wk of gestation. Furthermore, bile acids were predominantly conjugated to taurine while no secondary or unconjugated bile acids were found. The presence of other compounds in the bile was recognized but with the relatively crude procedures used in this study (2) their identification was not possible. Sharp et al. (4) later confirmed these findings using a conventional GLC technique, but the gestational age of the 14 fetuses considered in this study was not defined.

At birth, in the newborn infant, cholic acid has been reported to be the major biliary bile acid $(1,3)$. This is also true for adults 


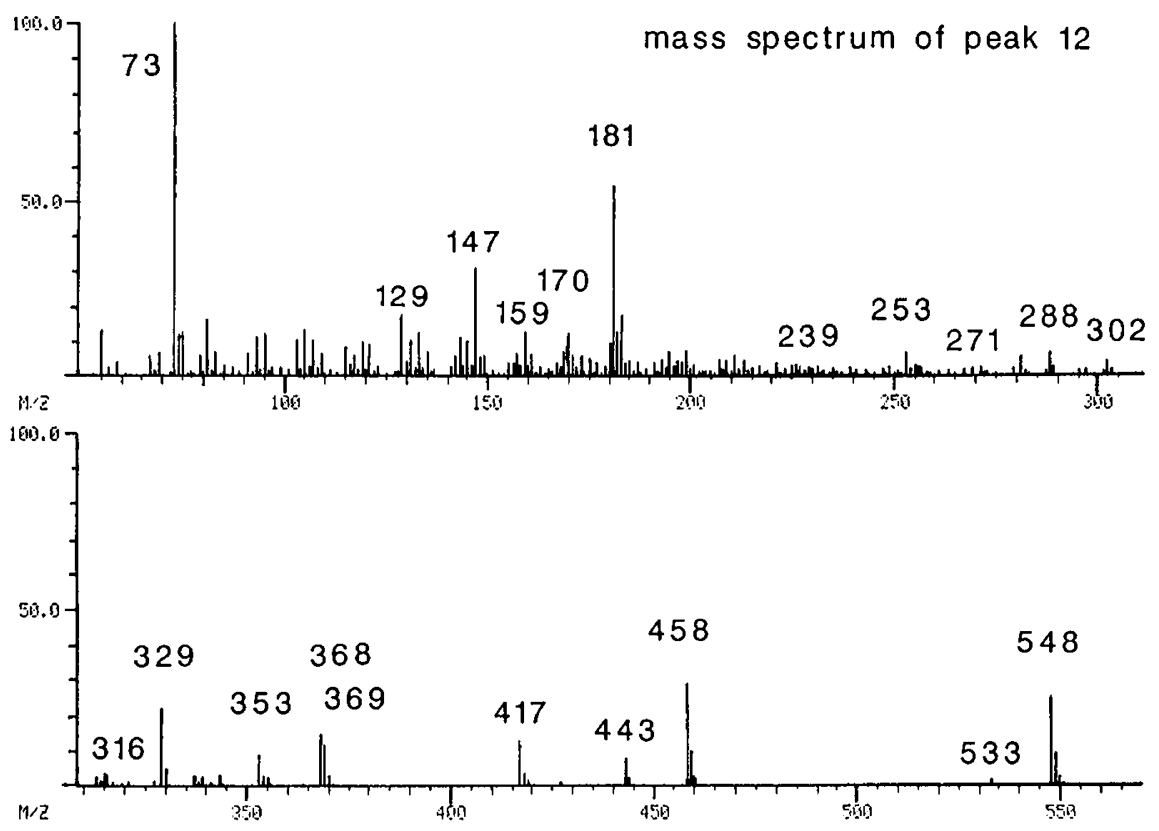

Fig. 2. MS (electron impact ionization, 70eV) for the Me-TMS ether derivative of a trihydroxy bile acid derivative eluted from the GLC column with retention time $32.73 \mathrm{MU}$.
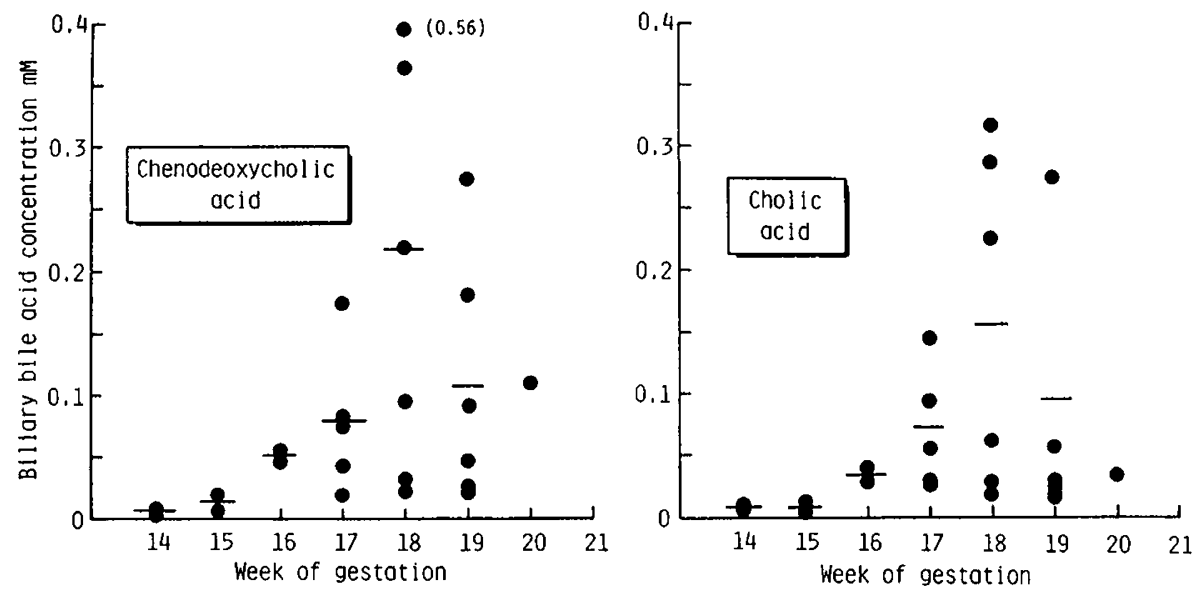

Fig. 3. Concentrations for chenodeoxycholic acid and cholic acid in samples of human fetal bile obtained between wk 14 and 20 of gestation.

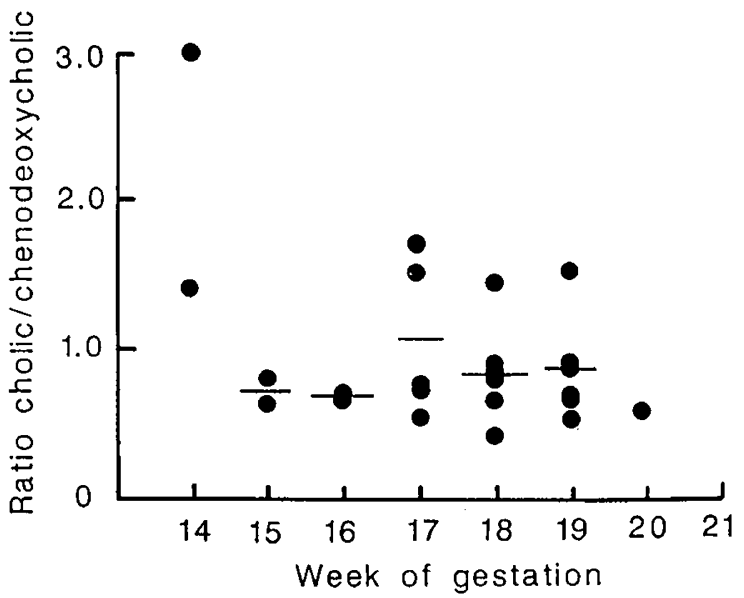

Fig. 4. The ratio of cholic:chenodeoxycholic acid concentrations in human fetal bile obtained between wk 14 and 20 of gestation.

(33). Our data are in agreement with the gross findings of these previous studies. Chenodeoxycholic acid was the predominant bile acid in fetal bile obtained from the 14th to 20th wh of gestation and secondary bile acids were not present in large amounts during this period. In our study, however, owing to the high sensitivity and chromatographic resolution of the analytical procedure, the bile acid profile of fetal bile is described for the first time. It is evident when these chromatograms (see Fig. 1) are compared with those obtained from low resolution conventional packed column GLC analysis that the application of these procedures is necessary to provide a more accurate definition of metabolism during development.

These preliminary observations revealed that $3 \beta$-hydroxy-5cholenoic acid and lithocholic acid were present only in trace amounts in fetal bile, despite these two bile acids having been found to be major components of meconium (34-36), but nevertheless consistent with a previous report using radioimmunoassay, which found relatively low concentrations of glycolithocholic sulfate in fetal serum (26).

Furthermore, fetal bile is characterized by the presence of many "atypical bile acids," which possess hydroxyl groups at positions $\mathrm{C1}, \mathrm{C} 6$, and one other position of unknown origin but in the steroid nucleus. 1-Hydroxy and 6-hydroxy bile acids are not normally found in the bile of healthy adults, but have been found in meconium $(35,36)$ and are therefore most likely to be of fetal hepatic origin. This is supported from a recent study where fetal hepatic microsomes in vitro were found to efficiently $1 \beta$-hydroxylate deoxycholic acid (10). Hyocholic acid $(3 \alpha, 6 \alpha, 7 \alpha-$ trihydroxy-5 $\beta$-cholanoic acid) was the major atypical bile acid 
identified in fetal bile and this is also the case for meconium (35, 36). In this study, no attempt was made to search for short-chain bile acids which have been recently identified in meconium and in the serum of patients with cholestatic syndromes (37-39) or to determine the mode of conjugation of the individual bile acid species; this is the focus of ongoing studies. It is of interest to note that bile acid metabolism in adults with severe cholestatic liver disease, which has been well documented (40), shows striking similarities to that seen in this study of the normal fetus.

From a quantitative point of view these data reveal for the first time in the human fetus a marked increase in biliary bile acid concentration from the 17 th wk of gestation which may be accounted for by an increase in hepatic synthesis. It would be of interest to know what the key determinants are in triggering the surge in biliary bile acid concentrations in early gestation. In a previous report, no correlation between serum bile acid concentrations and gestational age was found and this may be explained by a rapid equilibration of bile acids between the fetal and maternal compartments (25).

Finally, the finding of a lower ratio of cholic:chenodeoxycholic acid $[$ mean $=0.85 \pm 0.36(\mathrm{SD})]$ in fetal bile compared with the bile of newborn infants [approximate ratio 2.5 (1)] and adults (approximate ratio 1.6) appears to indicate an immaturity of the $12 \alpha$-hydroxylase enzyme system in the fetal liver (9). Since the cholic:chenodeoxycholic acid ratio remained relatively constant over the period of gestation considered in the study, this suggests that the activity of this enzyme must increase significantly in late gestation to account for the finding of an excess of cholic acid in newborn infant bile. This immaturity may account for the activation of other biosynthetic pathways, in particular $1 \beta$ - and $6 \alpha-$ hydroxylation of bile acids in fetal life. Studies in animals have shown a marked increase in hepatic enzymes concerned with bile acid synthesis during the perinatal period (41) and a rapid expansion of the bile acid pool (42). Our studies confirm that the development of bile acid synthesis in the human fetus proceeds quantitatively in a similar fashion and that qualitatively when compared to the adult human there are significant differences in the pathways of bile acid synthesis.

\section{REFERENCES}

I. Encrantz JC. Sjövall J 1959 On the bile acids in duodenal contents of infants and children. Clin Chim Acta 4:793-799

2. Poley JR. Dower JC. Owen CA. Stickler GB 1964 Bile acids in infants and children. J Lab Clin Med 63:838-846

3. Bongiovanni AM 1965 Bile acid content of gallbladder of infants, children and adults. J Clin Endocrinol Metab 25:678-685

4. Sharp HL. Peller J, Carey JB. Krist W 1971 Primary and secondary bile acids in meconium. Pediatr Res 5:274-279

5. Watkins JB. Ingall D. Szczepanik P. Klein PD, Lester R 1973 Bile salt metabolism in the human newborn. N Engl J Med 288:431-434

6. Watkins JB, Goldstein E, Coryer R, Brown ER, Eraklis A. Sulfation of bile acids in the fetus. In: Presig R, Bircher J (eds) The Liver, Quantitative Aspects of Structure and Function. Editio Cantor Aulendorf, Gstaad, pp 249-254

7. Clayton PT. Muller DPR. Lawson AM 1982 The bile acid composition of gastric contents from neonates with high intestinal obstruction. Biochem $\mathrm{J}$ 1982 206:489-498

8. Lawson AM. Setchell KDR. Clayton PT. Muller DPR 1983 Neonatal bile acid biosynthesis. In: Proceedings of 31 st Annual Conference on Mass Spectromctry and Allied Topics. pp 510-511

9. Gustafsson J 1985 Bile acid synthesis during development. Mitochondrial $12 \alpha-$ hydroxylation in human fetal liver. J Clin Invest 75:604-607

10. Gustafsson J. Andersson S. Sjövall J 1985 Bile acid metabolism during development: metabolism of taurodeoxycholic acid in human fetal liver. Biol Neonatc 47:26-31

11. Watkins JB. Perman JA 1977 Bile acid metabolism in infants and children. Clin Gastroenterol 6:201-218

12. Lester R. St Pyrck. J. Little JM. Adcock E 1983 Diversity of bile acids in the fetus and newborn infant. J Pediatr Gastroenterol Nutr 2:355-364

13. Barbara L. Lassari R, Roda A, Aldini R. Festi D, Sama C, Morselli AM, Collina A, Bazzoli F, Mazella G, Roda E 1980 Serum bile acids in newborn and children. Pediatr Res 14:1222-1225

14. Suchy FJ, Balistreri WF, Heubi JE, Searcy JE, Levin RS 1981 Physiologic cholestasis: elevation of the primary bile acid concentrations in normal infants. Gastroenterology 80:1037-1041

15. Balistreri WF, Heubi JE, Suchy FJ 1983 Immaturity of the enterohepatic circulation in early life: factors predisposing to "physiologic" malabsorption and cholestasis. J Pediatr Gastroenterol Nutr 2:346-354

16. Suchy FJ, Balistreri WF 1982 Uptake of taurocholate in hepatocytes isolated from developing rats. Pediatr Res 16:282-285

17. Suchy FJ. Courchene SM, Balistreri WF 1985 Ontogeny of hepatic bile acid conjugation in the rat. Pediatr Res 19:97-101

18. Heubi JE, Balistreri WF. Suchy F 1982 Bile salt metabolism in the first year of life. J Lab Clin Med 100:127-136

19. Heubi JE, Fondacaro JD 1982 Post-natal development of intestinal bile salt transport in the guinea pig. Am J Physiol 243:G189-194

20. Freese DK, Hason RF 1983 Neonatal cholestatic syndromes associated with alteration in bile acid synthesis. J Pediatr Gastroenterol Nutr 2:374-380

21. Holsti P 1960 Cirrhosis of the liver included in rabbits by gastric instillation of 3-monohydroxycholanoic acid. Nature 186:250

22. Javitt NB 1966 Cholestasis in rat induced by taurolithocholate. Nature 210:1262-1263

23. Palmer RH 1972 Bile acids, liver injury and liver disease. Arch Intern Med 130:606-617

24. Salen G, Dryszka H, Chen T, Saltzman WH, Mosbach EH 1974 Toxicity of chenodeoxycholic acid in rhesus monkeys. Lancet 2:1517-1518

25. Colombo C, Roda A, Roda E, Buscaglia M. Agnola AC, Fillippetti P, Ronchi M. Sereni F 1985 Correlation between fetal and maternal serum bile acid concentrations. Pediatr Res 19:227-231

26. Setchell KDR 1982 Liquid-solid extraction, liquid-gel chromatography and capillary column gas chromatography in the analysis of bile acids from biological samples. In: Barbara L, Dowling RH, Hoffman AF, Roda E (eds) Bile Acids in Gastroenterology. MTP Press LTD, Lancaster, England, pp 118

27. Setchell KDR. Matsui A 1982 Serum bile acid analysis Clin Chim Acta 127:1 17

28. Sctchell KDR I 984 Gas chromatography and mass spectrometry of bile acids. In: Proceedings of Ist International Symposium on Bile Acids in Hepatobiliary and Gastrointestinal Disease. IRL Press, Oxford, England, pp 63-78

29. Setchell KDR. Worthington J 1982 A rapid method for the quantitative extraction of bile acids and their conjugates from serum using commercially available reverse phase octadecylsilane bonded silica cartridges. Clin Chim Acta 125:135-144

30. Setchell KDR, Lawson AM, Tanida N, Sjövall J 1983 General methods for the analysis of bile acids and related compounds in feces. J Lipid Res 24:1085- 1100

31. Sjövall J, Lawson AM, Setchell KDR 1985 Mass spectrometry of bile acids. In: Law JH. Rilling HC (eds) Methods in Enzymology, vol III. Academic Press, London, pp 63-113

32. Lawson AM. Setchell KDR 1986 Mass spectrometry of bile acids. In: Setchell KDR, Kritchevsky D, Nair PP (eds) The Bile Acids, Vol 4. Plenum Press, New York (in press)

33. Sjövall J 1959 Dietary glycine and taurine on bile acid conjugation in man. Proc Soc Exp Biol Med 100:676-678

34. Sharp HL. Peller J. Carey JB Jr. Krivit W 1968 Lithocholic acid in meconium. Pediatr Res 2:293

35. Back P. Walter K 1980 Developmental pattern of bile acid metabolism as revealed by bile acid analysis of meconium. Gastroenterology 78:671-676

36. Street J, Balistreri WF. Setchell KDR 1986 Bile acid metabolism in the perinatal period-excretion of conventional and atypical bile acids in meconium. Gastroenterology 90:5(abstr)

37. Pyrek J St, Sterzycki R, Lester R, Adcock EW 1982 Constituents of human meconium II Identification of steroidal acids with 21 and 22 carbon atoms. Lipids 17:241-249

38. Lester R, Pyrek J St. Sterzycki R, Adcock EW 1982 Short-chain bile acids in meconium. Pediatr Res 16:169A

39. Pyrek J St. Little JM. Lester R 1984 Detection of 3-hydroxy-etianic and 3hydroxy-bisnorcholanoic acids in human serum. J Lipid Res 25:1324-1329

40. Almé B. Bremmelgaard A. Sjövall J. Thomassen P 1977 Analysis of metabolic profiles of bile acids in urine using a lipophilic anion exchanger and computerized gas-liquid chromatography-mass spectrometry. J Lipid Res 18:359-362

41. Daniellson H. Rutter WJ 1968 The metabolism of bile acids in the developing rat liver. Biochemistry 7:347-532

42. Little JM, Richey JE. Van Thiel DH, Lester R 1979 Taurocholate pool size and distribution in the fetal rat. J Clin Invest 63:1042-1049 